\title{
Developmental Changes in Agonist-Mediated Colonic Smooth Muscle Contraction in the Rabbit
}

\author{
HIDEKI YAGI, WILLIAM J. SNAPE, JR., AND PAUL E. HYMAN \\ Departments of Pediatrics, Medicine and Inflammatory Bowel Disease Center, Harbor-UCLA Medical Center, \\ Torrance, California 90509
}

\begin{abstract}
We studied smooth muscle strips from rabbit distal colon to determine age-related changes in lengthtension properties and agonist-mediated contraction. Strips from newborn (1-d-old) and weanling (11-wk-old) rabbits were oriented to measure isometric tension in longitudinal muscle. Active tension comprised $47 \pm 4$ and $75 \pm 5 \%$ of the total tension in the newborn and weanling, respectively. Total and active tensions in the weanling were greater than in the newborn $(p<0.001)$. Although the potencies for bethanechol were similar, the maximal response was nearly 9-fold greater in weanlings $\left(6900 \pm 292 \mathrm{mN} / \mathrm{cm}^{2}\right)$ versus newborns $\left(753 \pm 112 \mathrm{mN} / \mathrm{cm}^{2}\right), p<0.001$. Maximal stress increased with age for bethanechol, high extracellular potassium, substance $P$, neurokinin $A$, cholecystokinin octapeptide, bombesin, and serotonin. $\mathbf{E D}_{\mathbf{5 0}}$ for bethanechol, substance $P$, neurokinin $A$, and bombesin did not change with age. Serotonin was 12 times more potent in newborns versus weanlings $(p<0.05)$. In contrast, cholecystokinin octapeptide was five times less potent in newborns (18.6 $\mathrm{nM}$ versus $3.4 \mathrm{nM}$, respectively, $p<0.05$ ). Substance $P$ induced contractions were inhibited partially by atropine. We conclude that length-tension properties of longitudinal colonic smooth muscle differ, and responses to agonists increase with age. (Pediatr Res 29: 20-23, 1991)
\end{abstract}

\section{Abbreviations}

CCK-8, cholecystokinin octapeptide

5-HT, serotonin (5-hydroxy tryptamine)

$L_{0}$, optimal length

The functions of the distal colon to store and propel feces caudad for elimination take on importance immediately after birth. The control of colonic motility involves interactions among nerves, hormones, paracrine substances, and smooth muscle. Although the patterns of defecation in healthy human infants have been the subject of several studies (for review see Ref. 1), there has been little investigation of the changes in smooth muscle physiology that influence colonic function in the neonatal period.

Recently, our laboratory completed a survey of the age-related changes in gastric smooth muscle contraction in response to an array of putative smooth muscle agonists (2). There was a general trend for increasing force with increasing age, as well as agerelated decreases in potency for substance $\mathrm{P}$ and 5-HT, and

Received April 30, 1990; accepted September 4, 1990.

Correspondence: Paul E. Hyman, MD, Harbor-UCLA Medical Center, 1124 West Carson Street, C-1 Trailer, Torrance, CA 90502.

Supported in part by NIH Grants R29 HD22912 (P.E.H.) and R01 DK31147 (W.J.S.) and the Inflammatory Bowel Disease Center (P30-AM-32200) decreasing efficacy for bombesin. Our study extends the survey to the colon. Previous studies in rabbit (3) and cat (4) have described differences in length-tension properties and agonist responses in different anatomic regions of the colon. The purpose of our study was to systematically examine a group of agonists, and to identify those with changing effects during postnatal maturation of the colon.

\section{MATERIALS AND METHODS}

New Zealand White rabbits, newborns aged $1 \mathrm{~d}$ and weanlings (2.0-2.5 kg, approximately 1.1 wk old), were obtained from ABC Rabbitry, Pomona, CA or Irish Farms, Narco, CA. We purchased bethanechol chloride (Merck, Sharp \& Dohme, West Point, PA), atropine sulfate (Elkins-Sinn, Cherry Hill, NJ), and 5-HT (Sigma Chemical Co., St. Louis, MO). Substance P, neurokinin A, bombesin, and CCK-8 were obtained from Peninsula Laboratories, Belmont, CA.

We cut segments of the distal colon from the pelvic brim proximally, $5.0 \mathrm{~cm}$ long in weanling and $3.0 \mathrm{~cm}$ long in 1-d-old rabbits. We placed the tissues immediately into oxygenated Krebs-Ringer solution maintained at $37^{\circ} \mathrm{C}$. We removed the mucosa carefully, avoiding stretching or damaging the underlying muscle. We cut the muscle segments into full thickness strips measuring $1.0 \mathrm{~cm} \times 2 \mathrm{~mm}$ oriented in the axis of the longitudinal muscle. We transferred the muscle strips into a double-walled plastic perfusion chamber filled with Krebs-Ringer solution with the following composition (in $\mathrm{mM}$ ): $115 \mathrm{NaCl}, 4.6 \mathrm{KCl}, 2.1$ $\mathrm{MgCl}_{2}, 1.2 \mathrm{NaH}_{2} \mathrm{PO}_{4}, 21.2 \mathrm{NaHCO}_{3}, 2.5 \mathrm{CaCl}_{2}$, and 15.5 glucose. The chamber contents was maintained at $37^{\circ} \mathrm{C}$, and bubbled continuously with a gas mixture of $95 \% \mathrm{O}_{2}-5 \% \mathrm{CO}_{2}$. One end of the muscle was attached to a stationary clamp. The other end was attached via an inelastic wire to an isometric force transducer (Grass model FT03C; Grass Instruments, Quincy, MA).

The muscle tissue stabilized in the chamber for $1 \mathrm{~h}$, and then was stretched to an initial length such that any further stretch would increase tension at rest. Next, we stretched each strip progressively in 2-mm increments. Resting, active, and total tension was measured at each length. Resting tension is the tension developed by stretching without pharmacologic or electric stimulation. Active tension is the difference between resting tension and the peak tension after stimulation with $10 \mu \mathrm{M}$ bethanechol, the maximally effective dose. Total tension is the sum of resting and active tensions. After stimulation, washing each muscle strip with Krebs solution three times reduced the tension to the previous resting tension level. Muscle length was normalized to the length of maximal active tension development $\left(\mathrm{L}_{\mathrm{o}}\right)$. Tension was normalized to the active tension at $\mathrm{L}_{\mathrm{o}}$.

Drugs tested in these studies were dissolved in Krebs-Ringer solution and were added to each chamber to achieve the desired concentrations. After each administration, the muscle was 
washed free of the test agent and the tension allowed to return to its previous resting level. Contraction was expressed as stress per cross-sectional area $(\mathrm{A})$, calculated from the equation $\mathrm{A}=$ $\mathrm{M} / \mathrm{PI}$, where $\mathrm{M}$ was mass, $\mathrm{P}$ was density $(\mathrm{g} / \mathrm{mL})$ and numerically equal to the $\mathrm{sp} \mathrm{gr}$, and $\mathrm{l}$ was length of the muscle $(\mathrm{cm})$. The muscle weight was measured after experiments were completed, and after blotting to eliminate surface water.

A single agonist was tested on each muscle strip. After each incubation, the tissue was washed three times and allowed to reequilibrate for $15 \mathrm{~min}$. Dose-response curves were constructed beginning with the lowest dose and progressing to the maximal dose. After completion of the dose-response curve, strips were tested with $10 \mu \mathrm{M}$ bethanechol to assure that the strip had maintained its ability to contract.

To increase extracellular potassium concentration, we drained all buffer from the bath and immediately refilled the bath with a high-potassium buffer solution made by replacing $\mathrm{NaCl}$ with $\mathrm{KCl}$ at the concentrations noted. To study the effect of atropine, we first studied the response to each agonist alone. Tissues were washed, and $1 \mu \mathrm{M}$ atropine was added. After $5 \mathrm{~min}$ preincubation with atropine, the strips were incubated with the agonist. Response of the strip after the second incubation with agonist was compared with that after the first incubation and expressed as percent of the first response.

Data analysis. We calculated the agonist concentration required for a half maximal response $\left(\mathrm{ED}_{50}\right)$ and maximal stress using a nonlinear least squares computer program (5). We used unpaired $t$ tests or the Cochran-Cox test to compare $E_{50}$ or maximal stress between the age groups. Paired $t$ tests were performed for paired observations in the same animal. All data are expressed as mean $\pm \mathrm{SEM}$.

\section{RESULTS}

The length-tension properties of distal longitudinal muscle in newborn and weanling rabbits are shown in Figure 1. There was an age-related increase in resting tension at $\mathrm{L}_{\mathrm{o}}$ from $423 \pm 50$ to $1452 \pm 147 \mathrm{mN} / \mathrm{cm}^{2}(p<0.05)$. There was an age-related $10-$ fold increase in active tension from $386 \pm 69$ to $4062 \pm 395$ $\mathrm{mN} / \mathrm{cm}^{2},(p<0.001)$. Changes in these components resulted in an age-related increase in total tension from $809 \pm 120$ to 5604 $\pm 612 \mathrm{mN} / \mathrm{cm}^{2}(p<0.001)$. Thus, in the newborn, the active component was only $47 \pm 4 \%$ of the total tension, but in the weanling it was $75 \pm 5 \%(p<0.05)$.

All agonists stimulated dose-dependent tonic increases in tension. Tonic contraction persisted for at least $10 \mathrm{~min}$ in both age groups, after which the tissues were washed free of the test agent. Table 1 shows differences in the efficacy of agonist-induced contractions. Bethanechol stimulated the strongest responses in both newborn rabbits $\left(753 \pm 112 \mathrm{mN} / \mathrm{cm}^{2}\right)$ and weanlings $(6900$ $\pm 292 \mathrm{mN} / \mathrm{cm}^{2}$ ). The maximal contractions in response to potassium, substance $\mathrm{P}$, neurokinin A, CCK-8, bombesin, and 5 -HT were greater in weanlings compared with newborn rabbits $(p<0.01)$. The magnitude of increase varied from 9-fold for bethanechol to only 2 -fold for bombesin.

Table 2 shows the $\mathrm{ED}_{50}$ of agonist in newborn rabbits and weanlings. There were no age-related changes in potency for bethanechol, substance $\mathrm{P}$, neurokinin A, or bombesin. 5-HT was 12 times more potent in newborns $\left(\mathrm{ED}_{s 0}=4.4 \mathrm{nM}\right)$ than in weanlings $\left(\mathrm{ED}_{50}=53.7 \mathrm{nM}\right)(p<0.05)$. In contrast, $\mathrm{CCK}-8$ was five times less potent in newborns $\left(\mathrm{ED}_{50}=18.6 \mathrm{nM}\right)$ than in weanlings $\left(\mathrm{ED}_{50}=3.4 \mathrm{nM}\right)(p<0.05)$.

We studied the effect of $1 \mu \mathrm{M}$ atropine on stimulation by submaximal concentrations of each agonist to determine if antagonizing muscarinic cholinergic receptors might alter contractions. Atropine abolished contractions stimulated by bethanechol. A 5-min preincubation with atropine inhibited the contraction with $10 \mathrm{nM}$ substance $\mathrm{P}$ by $37 \%$ in newborns $(242 \pm 54$ to $\left.153 \pm 25 \mathrm{mN} / \mathrm{cm}^{2}, p<0.05\right)$ and $32 \%$ in weanlings (2852 \pm 329 to $\left.1951 \pm 283 \mathrm{mN} / \mathrm{cm}^{2}, p<0.05\right)$.

\section{DISCUSSION}

Our studies show that there is an age-related increase in the tension developed by colon muscle tissue. The increase is a summation of changes in both the noncontractile connective tissues of the extracellular matrix surrounding the myocytes (measured as part of resting tension) and the resting and active contraction of smooth muscle. The measurements of tension are corrected for surface area, and therefore represent maturation of the tissue structure and function, not increasing mass. These increases in tension may be necessary to maintain intraluminal pressure as the colonic lumen grows in diameter because of the direct relationship between wall tension and intraluminal pressure described by LaPlace's Law.

We chose to study longitudinal muscle because the colonic luminal circumference in newborns was too short for making muscle strips oriented to the circular muscle axis. Circular muscle is associated with strong, propulsive contractions, but the methodology precluded its study in this animal model. Longitudinal muscle may be important for the shuttling of intraluminal contents back and forth. The major postprandial transit pattern is a
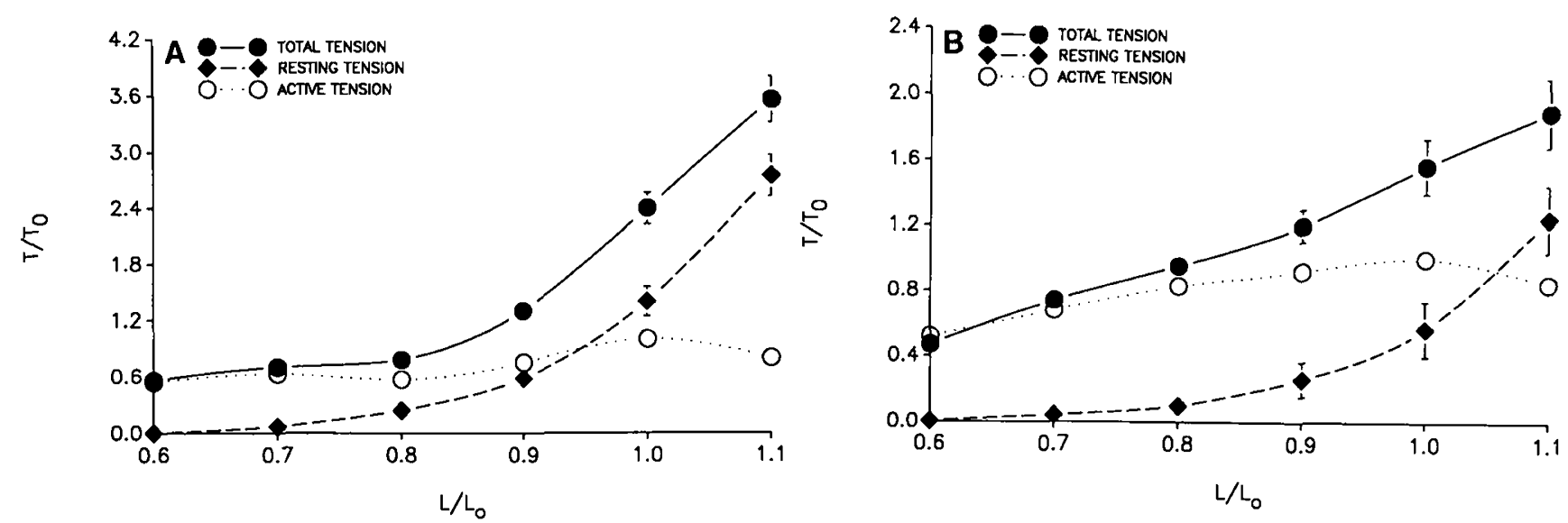

Fig. 1. Effect of age on length-tension curves for rabbit distal colonic longitudinal muscle stimulated with $10 \mu \mathrm{M}$ bethanechol. Muscle length Nas normalized to the optimal length, $\mathrm{L}_{\mathrm{o}}$. Tension $\left(T / T_{0}\right)$ was normalized to total tension at $\mathrm{L}_{\mathrm{o}}$. Left panel: newborn. Right panel: weanling. Data epresent the mean \pm SEM of five separate experiments. 
Table 1. Effect of age on efficacy

\begin{tabular}{lccc}
\hline \multicolumn{1}{c}{ Agonist } & Newborn & Weanling & $\begin{array}{c}\text { Ratio of age- } \\
\text { related increase }\end{array}$ \\
\hline Bethanechol & $753 \pm 112 \dagger$ & $6900 \pm 292$ & 9.2 \\
KCL & $494 \pm 62 \ddagger$ & $2471 \pm 255$ & 5.0 \\
Substance P & $472 \pm 49 \dagger$ & $4394 \pm 462$ & 9.3 \\
Neurokinin A & $629 \pm 50 \dagger$ & $3863 \pm 388$ & 6.1 \\
CCK-8 & $372 \pm 70 \dagger$ & $1151 \pm 147$ & 3.1 \\
Bombesin & $446 \pm 59 \dagger$ & $862 \pm 110$ & 1.9 \\
5-HT & $425 \pm 98 \ddagger$ & $2246 \pm 263$ & 5.3 \\
\hline
\end{tabular}

* Values were calculated from five or more experiments. Values are mean $\pm S E M$ in $\mathrm{mN} / \mathrm{cm}^{2}$ for active tension at $\mathrm{L}_{0}$.

$\dagger p<0.001$ compared to weanlings.

$\ddagger p<0.01$ compared to weanlings.

Table 2. Effect of age on potency

\begin{tabular}{lcc}
\hline \multirow{2}{*}{ Agonist } & \multicolumn{2}{c}{ ED $_{\text {so }}$} \\
\cline { 2 - 3 } \multicolumn{1}{c}{ Newborn } & Weanling \\
\hline Bethanechol $(\mu \mathrm{M})$ & $4.8(3.0-7.8)$ & $2.0(1.7-2.4)$ \\
$\mathrm{K}^{+}(\mathrm{mM})$ & $18.8 \pm 1.9$ & $16.1 \pm 0.9$ \\
Substance P $(\mathrm{nM})$ & $9.8(7.1-13.5)$ & $14.5(12.0-17.8)$ \\
Neurokinin A $(\mathrm{nM})$ & $6.3(3.6-10.7)$ & $6.0(4.2-6.6)$ \\
CCK-8 $(\mathrm{nM})$ & $18.6(11.9-29.0) \dagger$ & $3.4(2.6-4.4)$ \\
Bombesin $(\mathrm{nM})$ & $12.8(8.1-29.4)$ & $6.8(5.6-8.1)$ \\
5-HT $(\mathrm{nM})$ & $4.4(2.4-7.9) \dagger$ & $53.7(33.1-87.1)$ \\
\hline
\end{tabular}

* Values were calculated from six or more experiments. Except for potassium, $\mathrm{ED}_{50}$ were calculated in logarithmic units, so that estimates of central tendency are given as $95 \%$ confidence ranges rather than SEM $\dagger p<0.05$ compared to weanlings.

to-fro movement of contents, not absolute forward propulsion (6), so studies of longitudinal muscle may be relevant to colonic function.

A greater percentage of total stress is due to resting tension in the newborn compared with the weanling. This observation suggests that in the newborn, resistance of the bowel wall to stretch may facilitate the movement with a minimal expenditure of energy. Perhaps agonist-independent resting tension plays a more important role in the early postnatal period because neural coordination of agoinst-mediated contraction needs time to mature after birth.

In comparing the results in distal colon with our previous data in proximal stomach, there were some differences and some similarities. The general trend toward greater maximal force per unit surface area with age was found in both tissues, but was more impressive in colon (2). The efficacy of bethanechol increased 9-fold in colon, but only 3-fold in stomach; the efficacy of increasing extracellular potassium increased 2.5 -fold in stomach, but 5 -fold in colon. The results with potassium prove that factors other than receptors contribute to age-related increases in stress because $\mathrm{K}^{+}$-stimulated contraction is receptor independent.

Bombesin had the smallest increase in efficacy of all the agonists tested. Its relative efficacy decreased from 59 to $12 \%$ of the maximal response to bethanechol. In rabbit stomach, bombesin was the only agonist with age-related decreases in efficacy (2). Even so, the quantity of bombesin-like immunoreactivity found within the tissue did not change with age (7), and measurable amounts of bombesin were released by electrical field stimulation in adult rabbit colon (8). Based on relative efficacy, bombesin may have quantitatively greater influence on gastrointestinal motility in the neonatal period.

The efficacies of the agonists may provide some insights into the relative importance of each as a mediator of contraction. Maximally effective concentrations of the muscarinic agonist bethanechol consistently stimulated the largest contraction, but the neurokinin substance $P$ and neurokinin A had only slightly less efficacy. In the weanling, CCK-8, 5-HT, and bombesin had less than half the efficacy of bethanechol. There was a 9-fold agerelated increase in efficacy for bethanechol and for substance $P$, and a 6-fold increase for neurokinin $\mathrm{A}$. We found lesser increases in efficacy for the other agonists. Thus, not only did the relative order of efficacy remain bethanechol $>$ neurokinins $>$ others, but the absolute differences in efficacy grew larger with maturation.

Colonic motility depends on the complex interactions of neural and hormonal factors with the intrinsic properties of the colonic smooth muscle. We did not study the effect of neural blockade with tetrodotoxin, but we did assess the effect of the muscarinic receptor antagonist atropine. Atropine may work by binding to the myocyte or to muscarinic receptors on stimulatory or inhibitory neurons, but it does not abolish all potential neural activity. Atropine partially inhibited substance-P-stimulated contraction, as found previously in adult rabbit longitudinal colon muscle strips (9). This result suggests that exogenously applied substance $P$, at least in part, works through release of acetylcholine and so allowed a subtraction of the effects resulting from agonists stimulating acetylcholine release from the myenteric plexus. In contrast, neurokinin A stimulation was unaffected by atropine. These results differ from those in the rabbit stomach, where substance-P-stimulated contraction was not atropine sensitive (2).

The potency of CCK-8 increased with age. This finding suggests that CCK may assume more importance as a modulator of colon function with increasing postnatal age. In humans, there is a postprandial rise in plasma CCK occurring within $45 \mathrm{~min}$ after eating, suggesting that CCK may be involved in the regulation of postprandial colonic motility (10). There were agerelated increases in the number of CCK receptors in rat pancreas (11), and exogenous CCK did not stimulate human pancreatic secretion until $3 \mathrm{mo}$ of age (12). It is possible that in colon as well as in pancreas there is a postnatal maturation of the CCK receptor.

In contrast to CCK-8, the potency for 5-HT decreased with age. In an earlier study, we showed that the response to 5-HT was weakest in distal longitudinal muscle when compared with proximal and distal circular muscle and proximal longitudinal muscle from rabbit colon (13). Our present studies show that the relative efficacy of 5-HT decreases from $56 \%$ of the maximal response to bethanechol in the newborn to $33 \%$ of the maximal response to bethanechol in the weanling. These changes in potency and relative efficacy suggest that, at least in distal longitudinal muscle, 5-HT may have a quantitatively greater influence on contraction in the neonatal period.

In summary, this survey of putative agonists was used to identify ligands that elicit different responses in neonatal compared with weanling colon. We found these age-related changes: 1 ) increases in both resting and active tension; 2) increases in the maximal response of the tissue; 3 ) increasing potency for CCK; and 4) decreasing potency for 5-HT.

\section{REFERENCES}

1. Weaver LT 1988 Bowel habit from birth to old age. J Pediatr Gastroenterol Nutr 7:637-639

2. Tomomasa T, Yagi H, Kimura S, Snape Jr WJ, Hyman PE 1989 Developmental changes in agonist-mediated gastric smooth muscle contraction in the rabbit. Pediatr Res 26:458-461

3. Tucker HJ, Snape Jr WJ, Cohen S 1979 Comparison of proximal and distal colonic muscle of the rabbit. Am J Physiol 237:E383-E388

4. Merlo A, Cohen S 1988 Neuropeptide response and mechanics of proximal and distal feline colon in vitro. Am J Physiol 255:G787-G793

5. Dixon WJ (ed) BMDP Statistical Software 1985. University of California Press, pp 305-314 
6. Moreno-Osset E, Bazzocchi G, Lo S, Trombley B, Ristow E, Reddy SN, Villanueva-Meyer J, Fain JW, Jing J, Mena I, Snape Jr WJ 1989 Association between postprandial changes in colonic intraluminal pressure and transit. Gastroenterology 96:1265-1273

7. Yagi H, Snape Jr WJ, Hyman PE 1990 Perinatal changes in bombesinstimulated muscle contraction in rabbit stomach and colon. Gastroenterology (in press).

8. Snape Jr WJ, Kim BH, Willenbucher R, Koelbel CB, Mayer EA, Walsh JH 1989 Differences in response of proximal and distal rabbit colonic muscle after electrical field stimulation. Gastroenterology 96:321-326

9. Koelbel CB, Mayer EA, Reeve Jr JR, Snape Jr WJ, Patel A, Ho FJ 1989
Involvement of substance $\mathrm{P}$ in noncholinergic excitation of rabbit colonic muscle. Am J Physiol 256:G246-G253

10. Walsh JH, Lamers CCB, Valenzuela JE 1982 Cholecystokinin-octapeptide immunoreactivity in human plasma. Gastroenterology 82:438-444

11. Leung YK, Lee PC, Lebenthal E 1986 Maturation of cholecystokinin receptors in pancreatic acini of rats. Am J Physiol 250:G594-G597

12. Lebenthal E, Lee PC 1980 Development of functional response in human exocrine pancreas. Pediatrics 66:556-560

13. $\mathrm{Ng} \mathrm{WW}$, Jing J, Hyman PE, Snape Jr WJ 1990 Effect of S-hydroxytryptamine and its antagonists on colonic smooth muscle of the rabbit. Dig Dis Sci (in press)

\section{Announcement}

\section{Annual Meetings}

The American Pediatric Society, The Society for Pediatric Research, and The Ambulatory Pediatric Association will hold their annual meetings April 28-May 2, 1991 at the New Orleans Hilton and Rivergate Convention Center, New Orleans, LA. For further information, contact: APS/SPR Association Headquarters, 2650 Yale Blvd., S.E., Suite 104, Albuquerque, NM 87106, (505)764-9099, FAX (505)842-8227 or Ambulatory Pediatric Association, 6728 Old McLean Village, McLean, VA 22101, (703)556-9222. 